\title{
Post-traumatic untreated chronic osteomyelitis: an extreme presentation with severe complications
}

\author{
Catarina Sena Pinheiro Nunes, Filipa Macedo, Inês Gonçalves, Luísa Pinto
}

Internal Medicine Department, Hospital de Braga, Braga, Portugal

\section{Correspondence to} Dr Catarina Sena Pinheiro Nunes,

catarinaspn@hotmail.com

Accepted 25 October 2017

\section{DESCRIPTION}

An 89-year-old man presented to the hospital complaining of several episodes of lipotimia and non-specific malaise. Comorbidities included a right lower limb chronic osteomyelitis, as consequence of a trauma at the age of 12 years, with occasional bleeding, and which has never been medical or surgically treated before. He was haemodynamically stable with normal cardiac and pulmonary auscultation during the physical examination. The right lower limb revealed an extensive extremely putrefied and suppurative wound with bone exposition in which fragments could easily be removed (figure $1 \mathrm{~A}, \mathrm{~B}$ ). Considering the patient's complaints, a 12-lead ECG was performed and showed normal sinus rhythm with 2:1
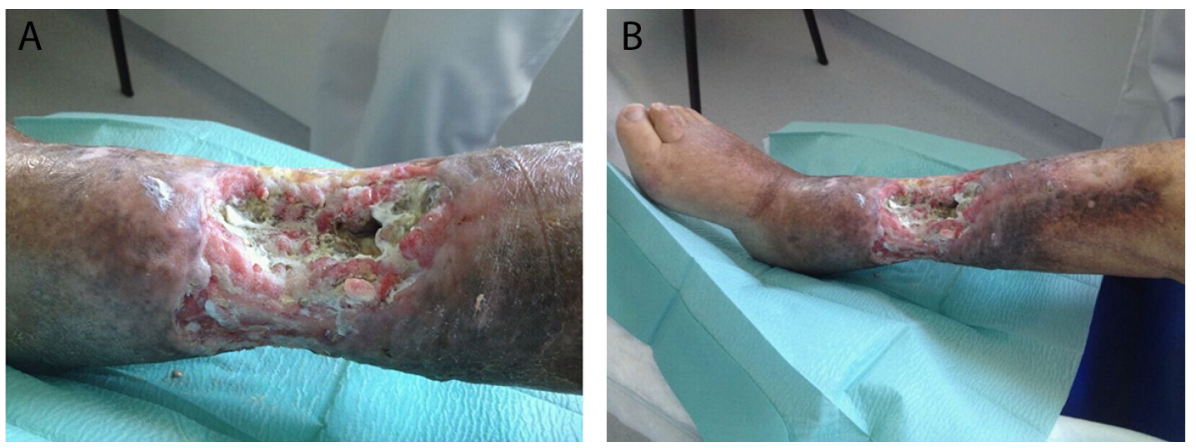

Figure 1 (A) and (B) Extensive putrefied and suppurative wound of the right lower limb with bone exposition secondary to a chronic untreated osteomyelitis.
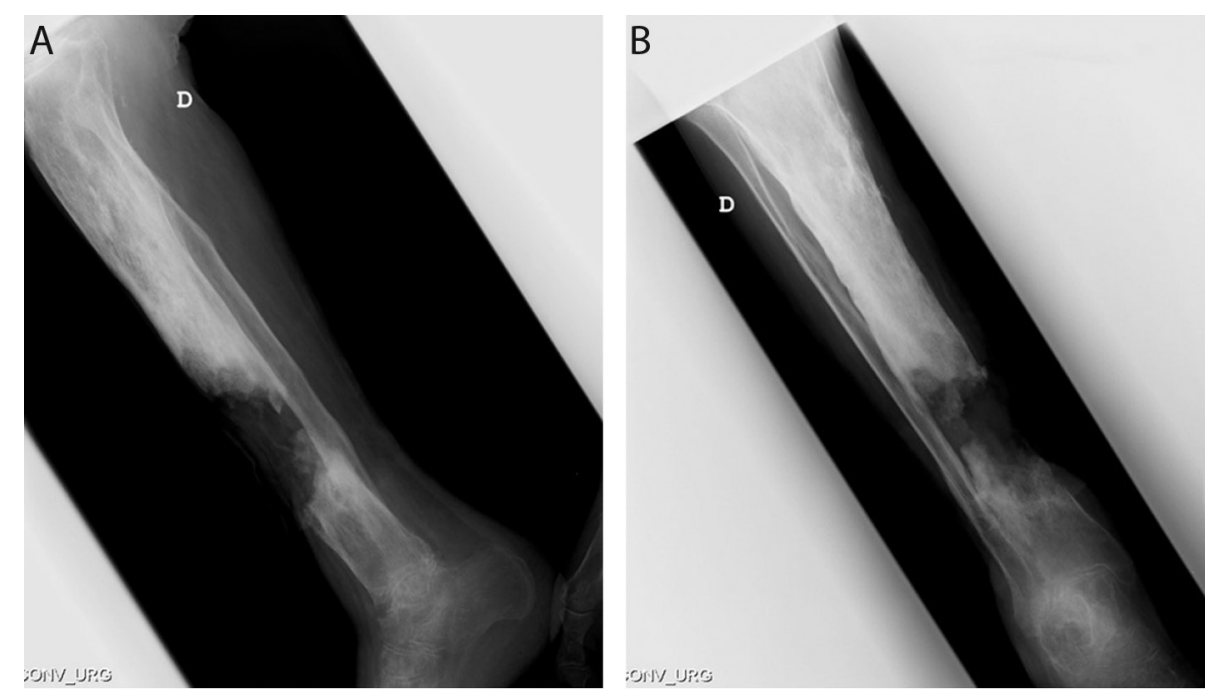

Figure 2 (A) and (B) Radiograph of the right lower limb demonstrating bone destruction of the distal third of the tibial diaphysis with proximal and medial third sclerosis, normal peronium, tibiotarsal arthrosis and osteoporosis of the calcaneus and tarsus. atrioventricular block, ST-segment elevation in the inferior leads and V6 and ST-segment depression in 1, V2, aVL and aVR. Patient denied chest pain. The laboratory investigation revealed a microcytic (reference range 13.5-17.0 g/dL) and reticulocytes of $2.6 \%$ (reference range $0.2 \%-2 \%$ ). The electrocardiographic changes were interpreted as a transient episode of myocardial ischaemia in context of severe anaemia (hypoperfusion of haemodynamic cause), despite the fact that the first hypothesis was of an acute myocardial infarction. There was no significant increase in the myocardial necrosis markers. After red blood cell transfusions, haemoglobin subsequently increased and electrocardiographic changes in ST segment disappeared. During 


\section{Learning points}

- Osteomyelitis is an inflammatory disorder of the bone. ${ }^{2}$ The diagnosis can be difficult and often delayed. ${ }^{1}$ Some acute osteomyelitis cases progress to chronic disease causing persistent morbidity, as they are characterised by frequent relapses. $^{12}$

- The infection control, the pain reduction and the reestablishment of the lost function are the primary goals of the treatment. ${ }^{1}$

- The post-traumatic osteomyelitis is one of the most frequent forms of bone infection. ${ }^{1}$ The treatment should be managed by a multidisciplinary team, in order to ensure an optimal outcome. $^{2}$

hospitalisation, the infected wound of the right lower limb had a permanent active bleeding and additional blood transfusion units were required. Right leg X-ray showed bone destruction of the distal third of the tibial diaphysis with proximal and medial third sclerosis, normal peronium, tibiotarsal arthrosis and osteoporosis of the calcaneus and tarsus (figure 2A,B). The microbiological study of the wound pus revealed a Psendomonas aeruginosa multisensible agent. The patient was first treated with daily dressings and ceftazidime antibiotic and then proposed for amputation. The surgery was successfully performed. This case demonstrates a severe, chronic and extremely exuberant presentation of an osteomyelitis, which led to serious complications. Untreated presentations, like the one we found in this case, are becoming less common, especially in industrialised countries. The post-traumatic and postsurgical osteomyelitis are the most frequent causes of bone infection found in developed countries. ${ }^{1}$ About $10 \%-30 \%$ of acute osteomyelitis progress to severe chronic disease that is difficult to treat and is characterised by recurrent relapses. ${ }^{12}$ Diagnosis requires an accurate medical history and clinical examination, laboratory analysis and X-rays. ${ }^{1}$ The radiological presentation commonly shows osteolysis and destruction of the bone, with sclerotic zones and periosteal bone appositions. ${ }^{1}$ There are no evidence-based guidelines about the treatment of chronic osteomyelitis; therefore, a decision should be made among a curative or a palliative approach taking into account the patient comorbidities. ${ }^{1}$ It is important to keep in mind that in post-traumatic osteomyelitis surgical treatment is crucial for a favourable outcome. ${ }^{1}$ The treatment goal is to control the infection, reduce pain and re-establish the affected function. ${ }^{1}$

Contributors CSPN is the first author and contributed to the case study and conception of the manuscript. FM, IG and LP contributed to the case study and critical review. LP supervised the writing critically. All the authors have made significant contributions for this manuscript. All authors read and approved the final manuscript.

Competing interests None declared.

Patient consent Obtained.

Provenance and peer review Not commissioned; externally peer reviewed.

(c) BMJ Publishing Group Ltd (unless otherwise stated in the text of the article) 2017. All rights reserved. No commercial use is permitted unless otherwise expressly granted.

\section{REFERENCES}

1 Walter G, Kemmerer M, Kappler C, et al. Treatment algorithms for chronic osteomyelitis. Dtsch Arzteb/ Int 2012;109:257-64.

2 Rao N, Ziran BH, Lipsky BA. Treating osteomyelitis: antibiotics and surgery. Plast Reconstr Surg 2011;127:177S-87.

Copyright 2017 BMJ Publishing Group. All rights reserved. For permission to reuse any of this content visit

http://group.bmj.com/group/rights-licensing/permissions.

BMJ Case Report Fellows may re-use this article for personal use and teaching without any further permission.

Become a Fellow of BMJ Case Reports today and you can:

- Submit as many cases as you like

- Enjoy fast sympathetic peer review and rapid publication of accepted articles

- Access all the published articles

Re-use any of the published material for personal use and teaching without further permission

For information on Institutional Fellowships contact consortiasales@bmjgroup.com

Visit casereports.bmj.com for more articles like this and to become a Fellow 